Supporting Information

\title{
Improved photophysical properties of ionic material- based combination chemo/PDT nanomedicine
}

Samantha Macchi', Mohd Zubair ${ }^{b}$, Robert Hill ${ }^{a}$, Nabeel Alwan ${ }^{a}$, Yusuf Khanc, Nawab Ali ${ }^{b}$,

Grégory Guisbiers ${ }^{d}$, Brian Berry, and Noureen Siraja * *

[a] Department of Chemistry. University of Arkansas at Little Rock. 2801 S. University Ave.,

Little Rock, AR 72204

[b] Department of Biology. University of Arkansas at Little Rock. 2801 S. University Ave.,

Little Rock, AR 72204

[c] Department of Electrical and Computer Engineering, University of Texas at Austin, Austin,

TX 78712, USA

[d] Department of Physics and Astronomy. University of Arkansas at Little Rock.2801 S.

University Ave., Little Rock, AR 72204 
*Corresponding author: Noureen Siraj (E) nxsiraj@ualr.edu (O) 501-916-6544

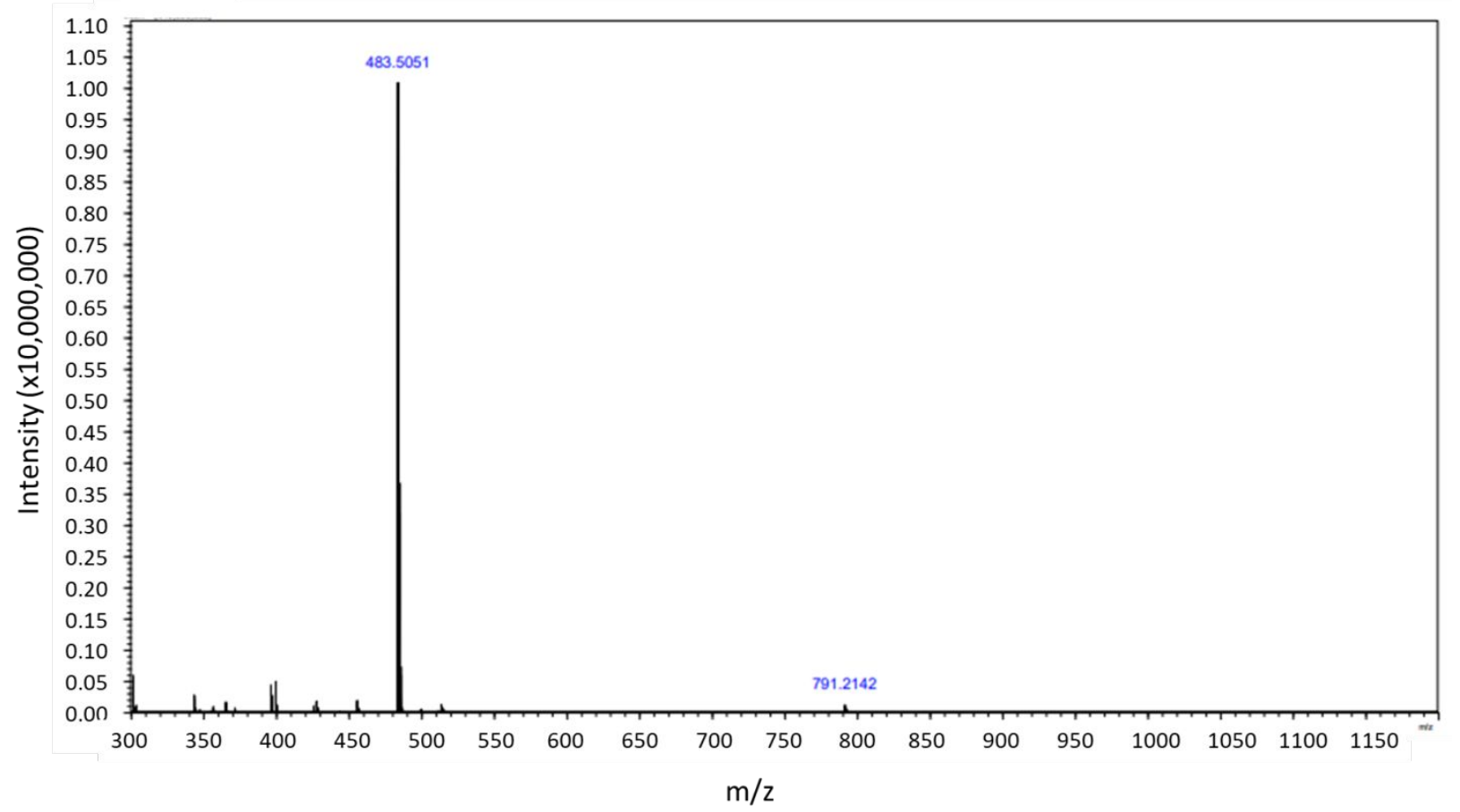

Figure S1. ESI-MS of $\left[\mathrm{P}_{66614}\right]_{4}[\mathrm{TCPP}]$ in positive ion mode 


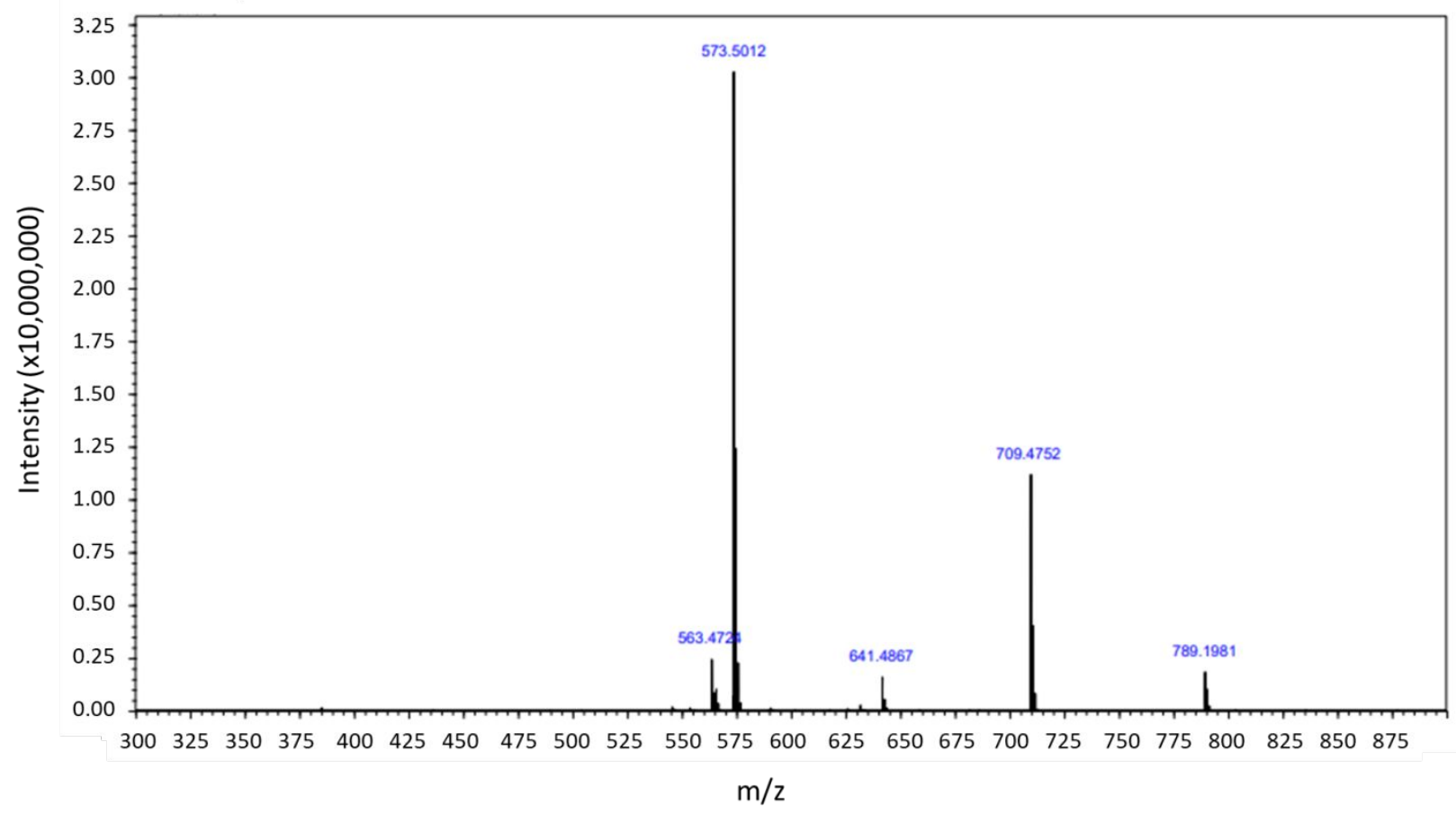

Figure S2. ESI-MS of $\left[\mathrm{P}_{66614}\right]_{4}[\mathrm{TCPP}]$ in negative ion mode

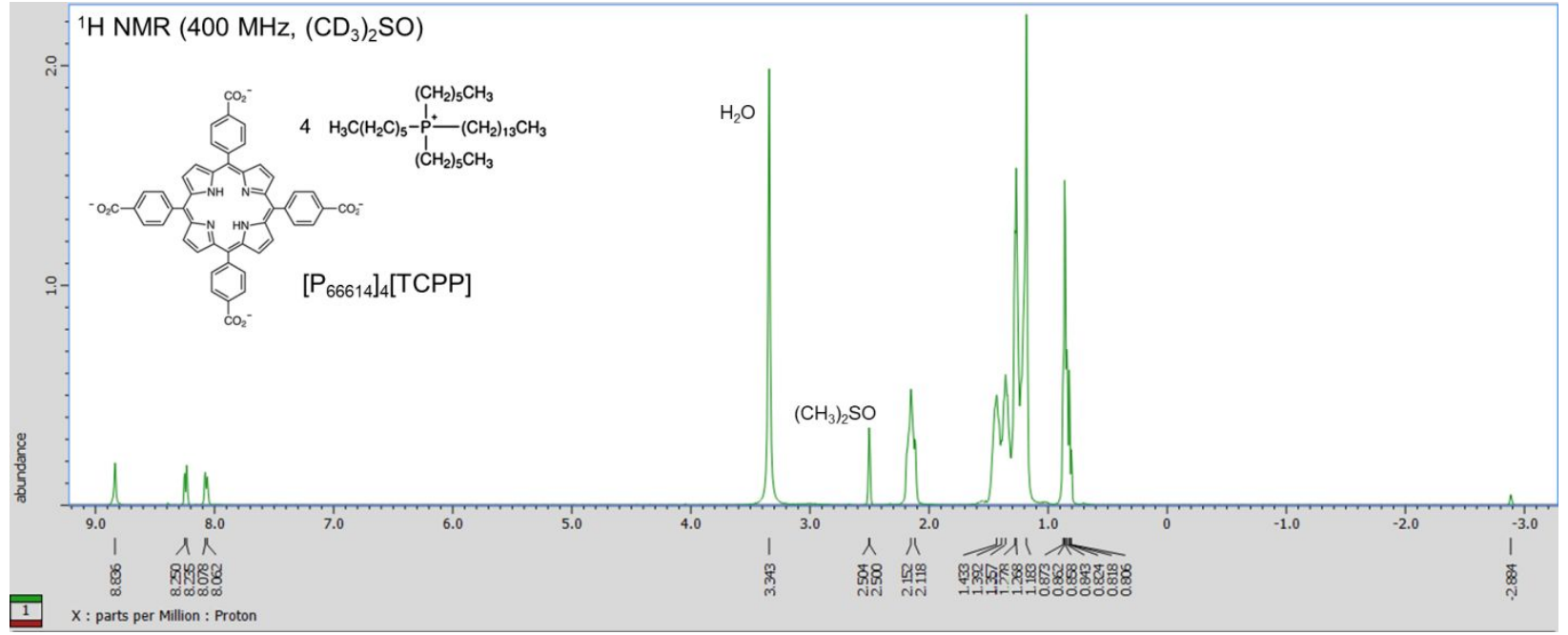

Figure S3. NMR spectra of $\left[\mathrm{P}_{66614}\right]_{4}[\mathrm{TCPP}]$ 


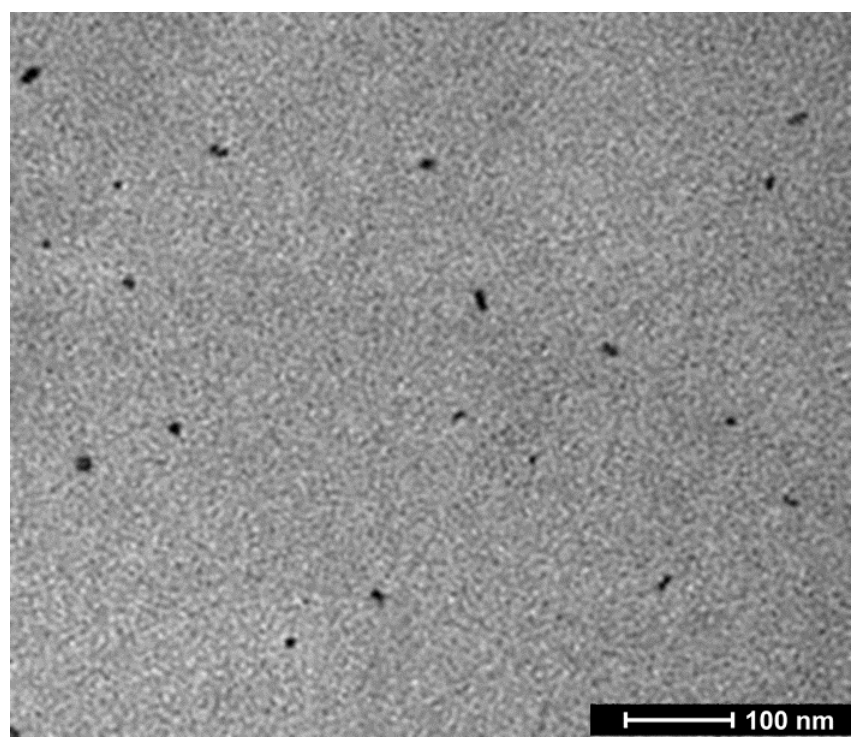

Figure S4. TEM image of $\left[\mathrm{P}_{66614}\right]_{4}[\mathrm{TCPP}] \mathrm{INMs}$
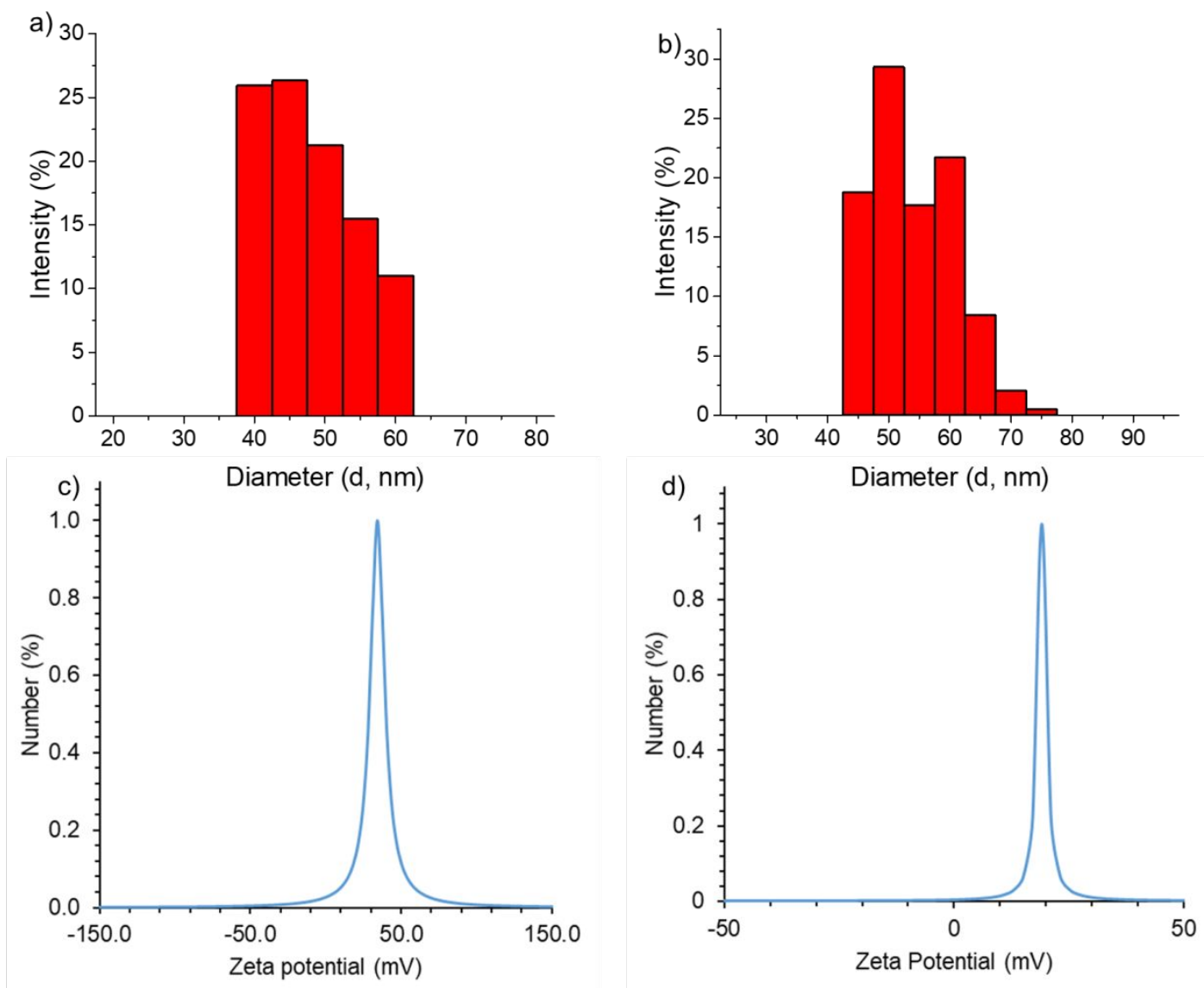
Figure S5. Particle size distribution of a) $\left[\mathrm{P}_{66614}\right]_{4}[\mathrm{TCPP}]$ INMs and b) FA-[ $\left.\mathrm{P}_{66614}\right]_{4}[\mathrm{TCPP}]$ coated INMs at a concentration of $50 \mu \mathrm{M}$ and zeta potential distribution of the same suspension of c) $\left[\mathrm{P}_{66614}\right]_{4}[\mathrm{TCPP}]$ INMs and d) FA-[P 66614$]_{4}[\mathrm{TCPP}]$ coated INMs 

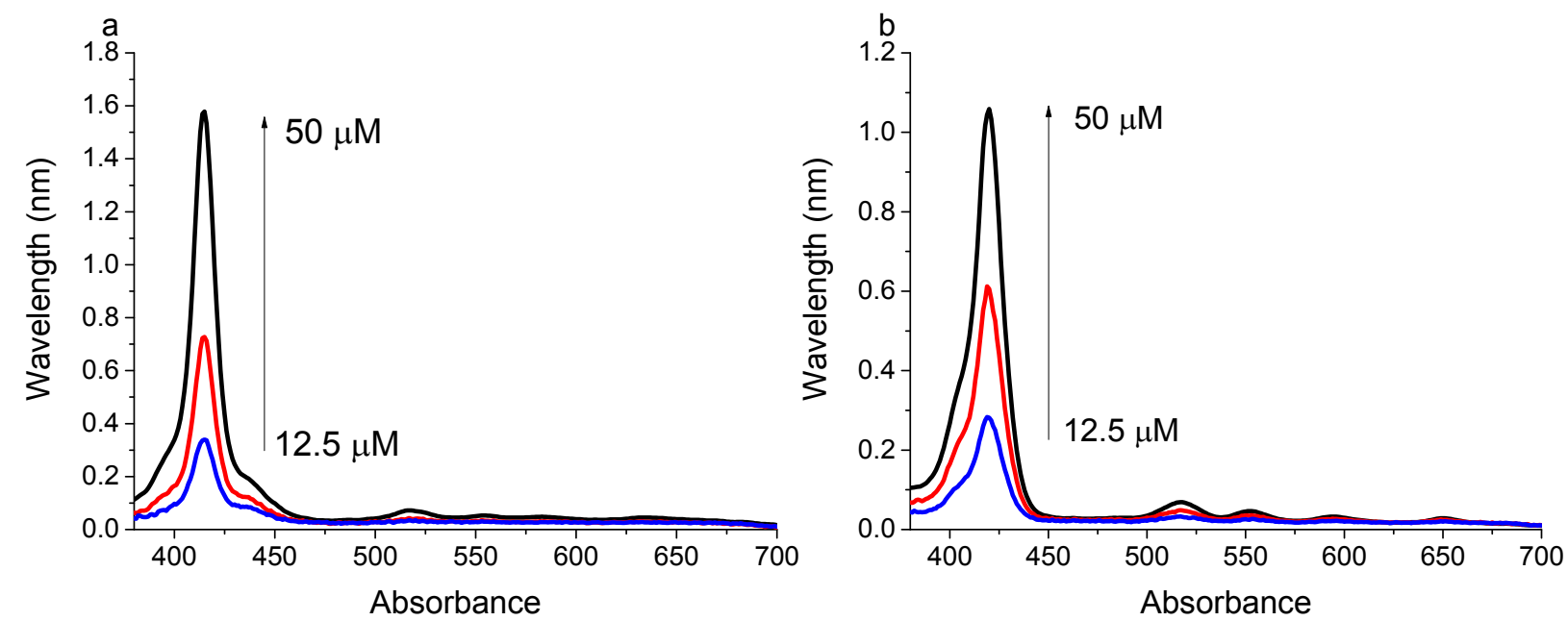

Figure S6. Absorbance of a) TCPP and b) $\left[\mathrm{P}_{66614}\right]_{4}[\mathrm{TCPP}]$ in water at high concentration using sub-micron 4 -sided cuvet $(0.3 \mathrm{~cm}$ path length).

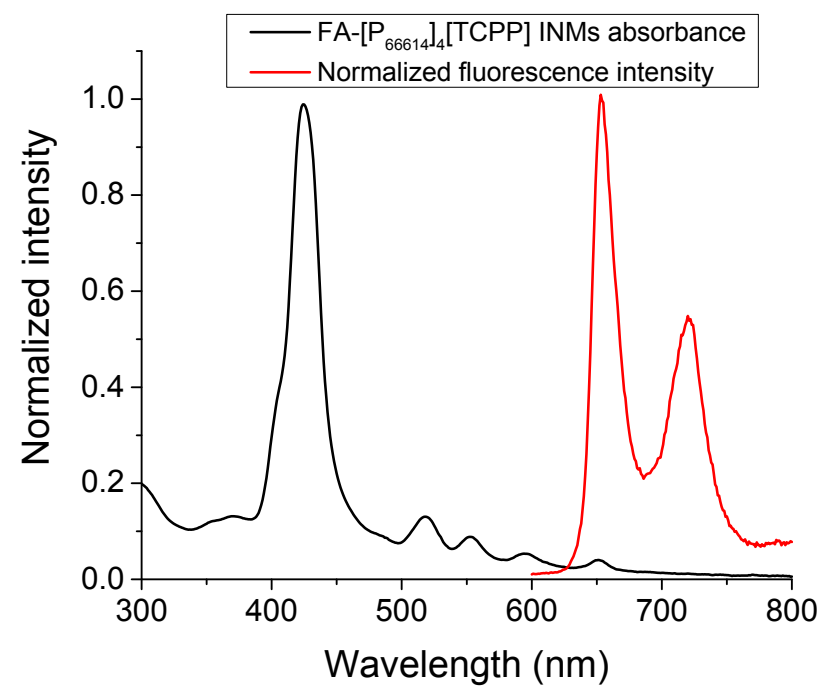

Figure S7. FA-coated NP absorbance (black line) and fluorescence emission (red) 


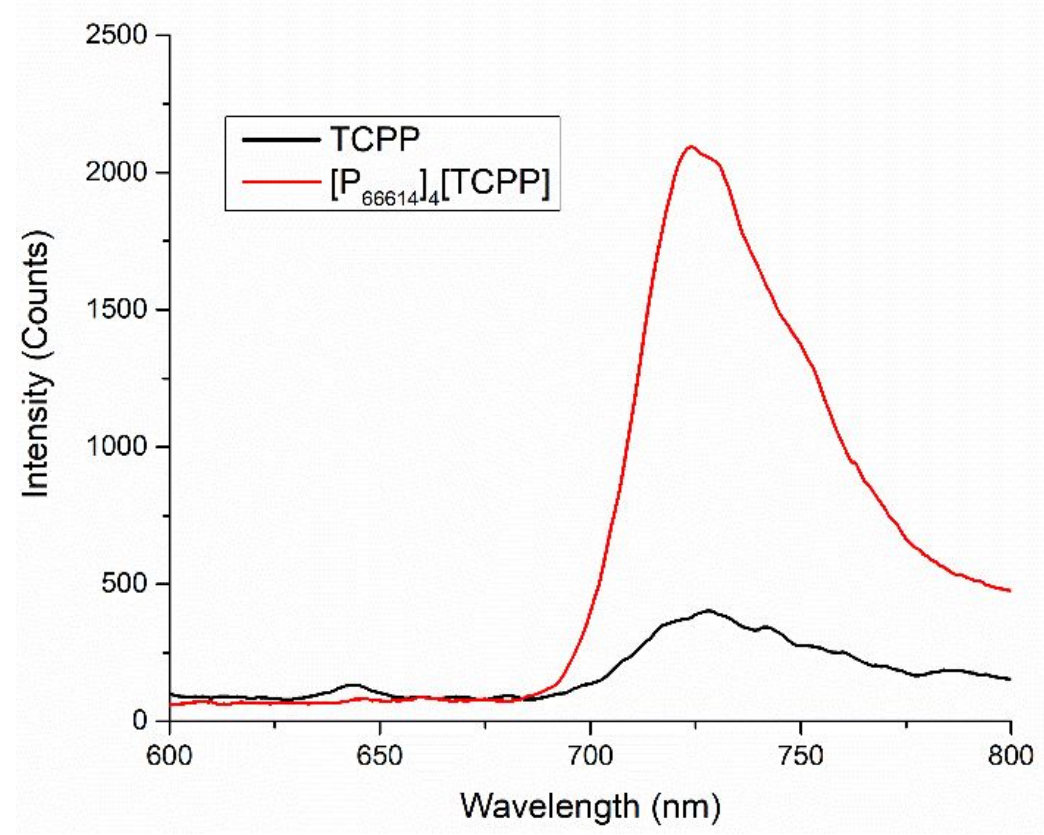

Figure S8. Phosphorescence of $1 \mu \mathrm{M}$ TCPP and $\left[\mathrm{P}_{66614}\right]_{4}[\mathrm{TCPP}]$ in ethanol at $77 \mathrm{~K}$ at an excitation wavelength of $420 \mathrm{~nm}$ and at $0.1 \mathrm{~ms}$ delay time. 


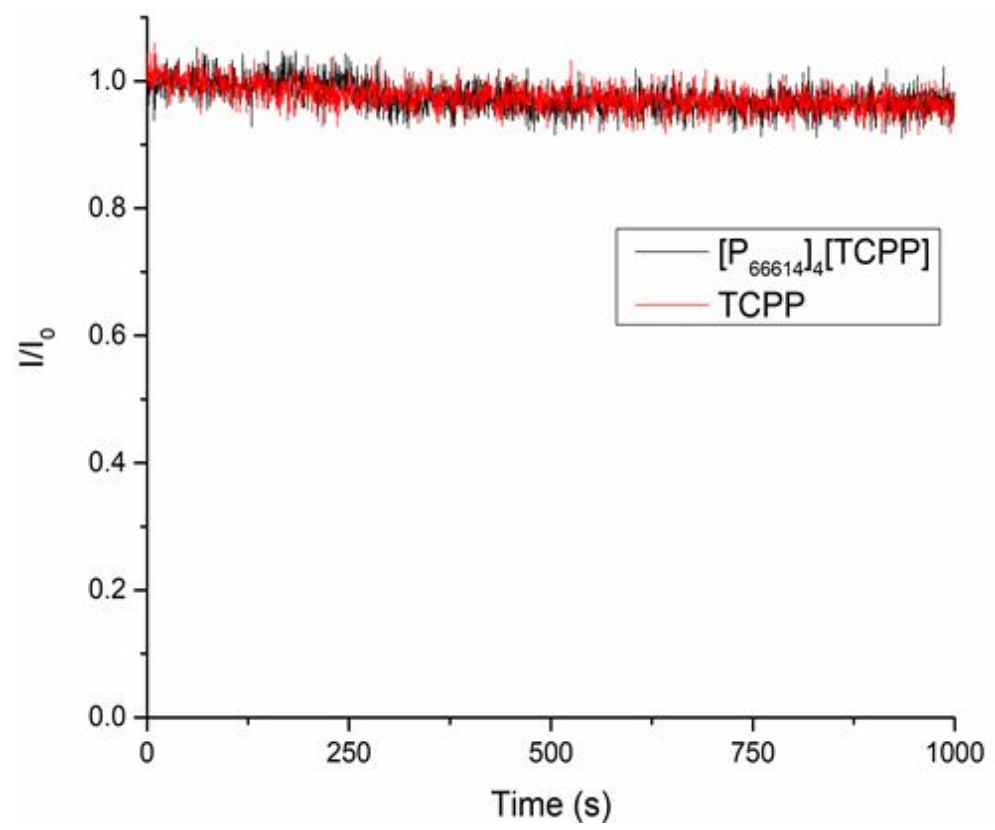

Figure S9. Photostability of $\left[\mathrm{P}_{66614}\right]_{4}[\mathrm{TCPP}]$ and TCPP parent in ethanol over $1000 \mathrm{~s}$. The ratio represents the fluorescence intensity (I) at any time over the initial fluorescence intensity $\left(I_{0}\right)$ of each compound.
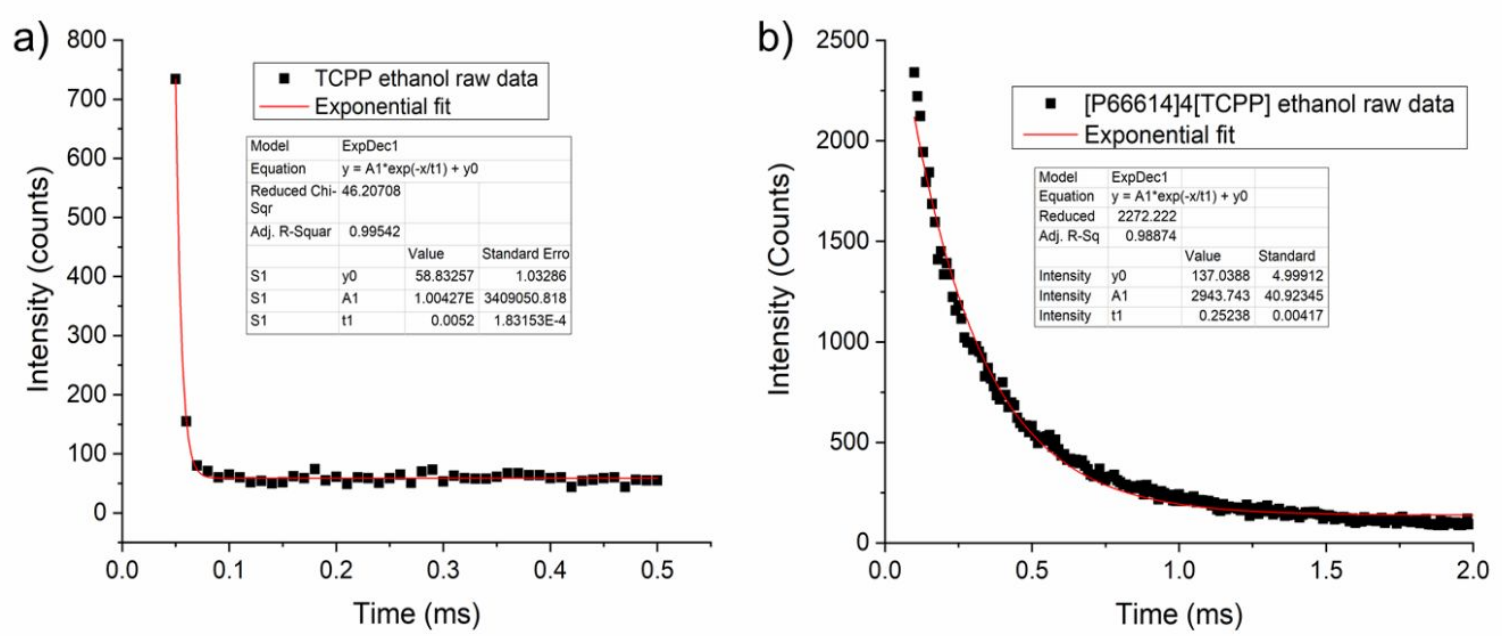
Figure S10. Phosphorescence decay profile of a) TCPP and b) $\left[\mathrm{P}_{66614}\right]_{4}[\mathrm{TCPP}]$ in ethanol at $77 \mathrm{~K}$ with 1 exponential fit of data
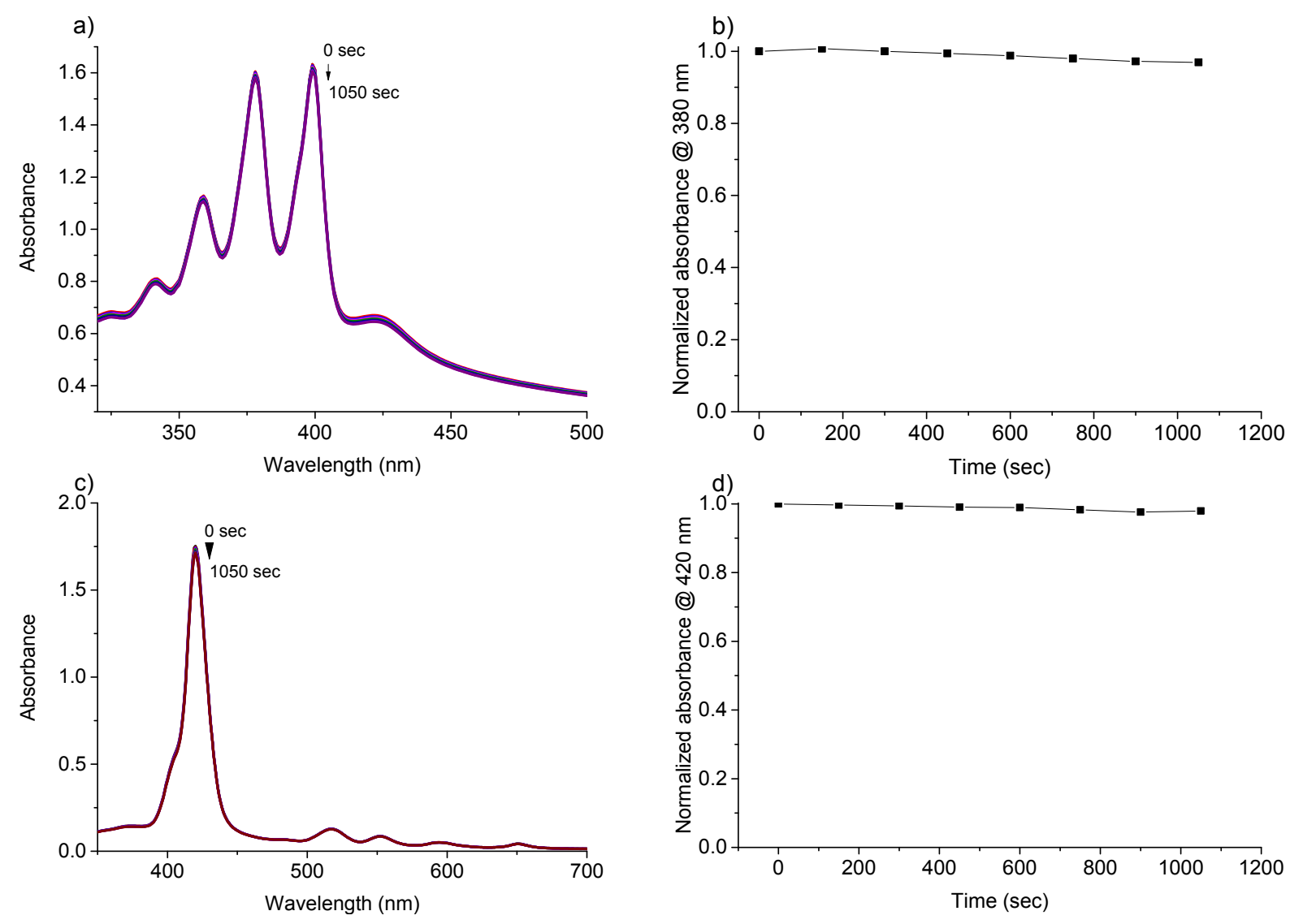

Figure S11. a) Absorbance of probe (ABDA) after irradiation for $1050 \mathrm{sec}$ and b) normalized absorbance monitored at $380 \mathrm{~nm}$ during irradiation at $420 \mathrm{~nm}$. c) Absorbance of $\left[\mathrm{P}_{66614}\right]_{4}[\mathrm{TCPP}]$ INMs after irradiation for $1050 \mathrm{sec}$ and d) normalized absorbance monitored at $420 \mathrm{~nm}$ during irradiation at $420 \mathrm{~nm}$. 


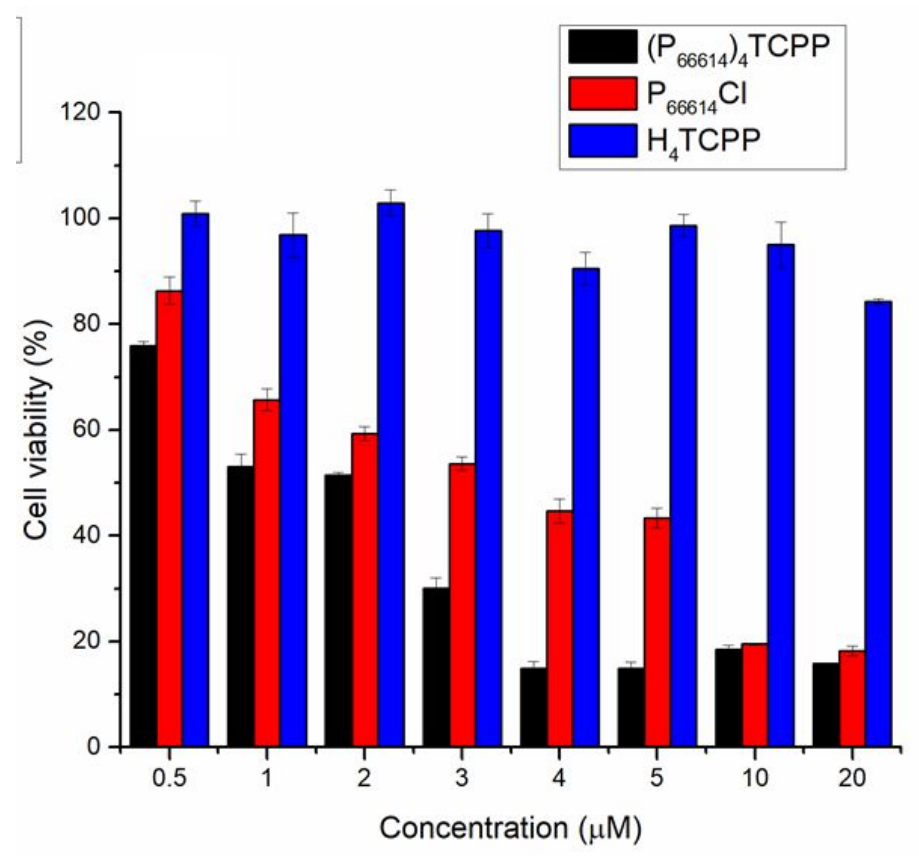

Figure S12. Cytotoxicity of parent compounds and unmodified nanodrug incubated for $24 \mathrm{hr}$ in MCF-10A cells

Table S1. Calculated $\mathrm{IC}_{50}$ concentrations $(\mu \mathrm{M})$ of drugs in MCF-7 at $10^{4}$ cells per well after $4 \mathrm{hr}$ in dark (-) and light $(+)$ conditions.

\begin{tabular}{|l|l|l|}
\hline Sample & With irradiation $(+)$ & W/out irradiation $(-)$ \\
\hline TCPP & 27.4 & N/A \\
\hline$\left[\mathrm{P}_{66614}\right]_{4}[$ TCPP $]$ & 5.2 & 7.3 \\
\hline
\end{tabular}

